\title{
HYPERBOLE IN SONG LYRICS OF SEMPITERNAL ALBUM BY BRING ME THE HORIZON
}

\author{
Putu Indira Cika Mantika Sari ${ }^{1}$ I Dw Ayu Devi Maharani Santika², \\ I Wayan Juniartha ${ }^{3}$ \\ Mahasaraswati Denpasar University, Indonesia ${ }^{123}$ \\ indiracika12@gmail.com, devimaharani17@gmail.com, \\ jjuniartha@gmail.com
}

\section{Journal History}

Submitted 26 th December 2021

Revised 15 th January 2022

Accepted 17th January 2022

Published 24th January 2022

Keywords:

Hyperbole, Meaning, Bring Me The Horizon

\begin{abstract}
This research aims to identify and to analyze the meaning of hyperbole applied in the song lyrics of Sempiternal album by Bring Me the Horizon. The data were collected from eleven songs within the album. The research applied descriptive qualitative analysis using theory of figurative language by Knickerbocker and Renninger (1963) to determine the lyrics that contain hyperbole and theory of meaning by Leech (1981) to analyze the meaning of the hyperbole. The data in this study were presented descriptively. The result of the analysis shows thirteen hyperboles are found in the lyrics. The meanings found based on the lyrics with hyperbole consist of three kinds, namely connotative, affective, and conceptual. The dominant meaning is connotative as the hyperbole cannot be interpreted lexically.
\end{abstract}




\section{INTRODUCTION}

A literary work is commonly composed with language that the meaning is beyond dictionary. It means that the words cannot be interpreted lexically or has metaphorical meaning. Usually, this is called as stylistic choice of the author. One of the variations in stylistic choice is hyperbole, which is a part of figurative language. According to Knickerbocker and Renninger (1963: 367), figurative language is sometimes called metaphorical language, or simply metaphor, because its Greek ancestor, the word is derived from the word Metaphereien that means to carry meaning beyond its literal meaning (meta $=$ beyond + pherin = to ing -i.e., to bring beyond). One type of figurative language is hyperbole. Hyperbole is an exaggeration used for special purposes as stated by Knickerbocker and Renninger (1963: 367). There is abundance of literary works that use hyperbole and one of them is song lyrics. Understanding the lyrics well, especially ones with hyperbole, is very important as it contributes to the comprehension of the message. A failure of communication can happen when the message of the song is misunderstood. Without the ability to fully comprehend songs with figurative language, to interpret the songs will be much likely difficult. Even, the interpretation can be different than the supposed one. Particularly in songs with many hidden meanings, it is required to understand the lyrics well, including the ones with hyperbole.

Studies about hyperbole have been done previously by several research. Articles from McCarthy and Carter (2004) entitled “There's Million of Them": Hyperbola in Everyday Conversation, Ardiansyah and Mandarani (2018) entitled An Analysis of Figurative Language Elements upon an American Short Story Entitled "The Monkey's Paw", Huang (2020) entitled Hyperboles in Advertising: A Serial Mediation of Incongruity and Humour, Setiawati and Maryani (2018) entitled An Analysis of Figurative Language in Taylor Swift's Song Lyrics, and Wibisono and Widodo (2019) entitled An Analysis of Figurative Language in Online Short Story Posted on the Jakarta Post have researched the similar topic of hyperbole. These research focus on hyperbole that used in many fields. To make this study different from other research, the study focuses in analyzing hyperbole and its meaning in a song. It is a common to use figurative languages in a song. They are used to beautify the lyrics, as well as to create more variant of sentences. They also help to deliver the meaning intended by the song writer or the singer.

\section{METHODS}

The data in this study were collected from the eleven songs within Sempiternal album by Bring Me the Horizon. The songs are Can You Feel My Heart, The House Of Wolves, Empire (Let Them Sing), Sleepwalking, Go To Hell, For Heaven's Sake, Shadow Moses, And The Snakes Start To Sing, Seen It 
All Before, Anti-vist, Crooked Young, Hospitals For Souls. The album was the fourth album by the band. The album was chosen because all the songs in this album also used a lot of figurative language that can be analyzed. This album debuted at No. 3 on the UK Album Chart and is their second consecutive album to be at the ARIA Charts in Australia. It also managed to reach No. 11 on the US Billboard 200 with 27,522 first-week sales, making Sempiternal the band's highest chart album in America.

To collect the data, this study applied observation and note-taking techniques. Qualitative approach was applied in analyzing the data which are based on the theory proposed by Knickerbocker and Renninger (1963) and Leech (1963).

Knickerbocker and Renninger (1963) stated that hyperbole is an exaggeration used for special purposes. A hyperbole also usually explains illogical thing to deliver meaning beyond the words used. For example, go catch the falling star, the previous sentence is called hyperbole because it explains an illogical thing because no one can capture the falling star and we know that the star is a planet in the sky that is larger than our size. Furthermore, the writer does not command to catch the actual falling star. In this scenario, falling star is a dream and a wish. Thus, in that sentence, the writer gives a message that we can go and catch our dreams and wishes in this life.

The second theory proposed by Leech (1981) was applied to analyze the meaning. Seven kinds of meaning proposed by Leech are conceptual, connotative, affective, associative, collective, thematic, and intended meaning. Conceptual meaning is a literal meaning from dictionary. Connotative meaning is the communicative significance that the word, or simply meaning beyond the words. Usually, the meaning is metaphorical. Affective meaning is a meaning that has personal feeling of someone that he/she wants to share. Collective meaning is a meaning that shares similar meaning with specific terms. Associative meaning is a meaning that is associated with an object to represent certain object. Thematic meaning is a meaning that is affected by how a speech or a sentence is organized. Intended meaning is a meaning that has utterance or a motive to make someone to do something.

The data were presented using informal presentation with descriptive analysis. The analysis that was presented consisted of the data, the analysis of hyperbole, and lastly, the analysis of the meaning. The sequences were applied to provide better and effective structure to understand the analysis. 


\section{RESULTS AND DISCUSSION}

\section{RESULTS}

According to the analysis result, there are thirteen hyperboles found in seven songs. Those songs are Can You Feel My Heart, Empire Let Them Sing, Sleepwalking, Go to Hell for Heaven's Sake, The House of Wolves, Seen It All Before, and And the Snakes Start to Sing. For the result of meaning analysis, there are only three out of seven types of meaning found in this study. They are connotative, affective, and conceptual meaning.

\section{DISCUSSION}

This part explains the hyperbole analysis of the song lyrics of Sempiternal album. There are thirteen data obtained from the song lyrics of the album presented in this part.

\section{Data 1:}

\section{[1] Can you feel my heart (Can You Feel My Heart)}

This data contains an exaggerated expression so it can be categorized as hyperbole. Heart is a part of human organ where is located inside a body. It is an illogical thing to do and it is impossible to feel one's heart. The lyrics expresses a question to other person if she/he can understand the feeling that someone has for him/her. Since the figurative language delivers another meaning besides the true meaning, this sentence considered to have a connotative meaning. It means someone wants to make sure that other person that he loves understands his feeling. As an addition, this figurative language also used to express an emotion and feeling of someone, then the sentence also has an affective meaning.

\section{Data 2:} Heart)

[2] I can't drown my demons; they know how to swim (Can You Feel My

The data above states that a demon can be drowned. Drowning means killing someone by holding them underwater until they face death. However, a demon is known as a spirit of devil, it is an immortal thing. It cannot be touched and held. Therefore, it is irrational if someone can have an ability to drown a demon. Hence, this part of the song lyrics is exaggerated. Furthermore, the phrase "my demons" is also an exaggerated idea as demon is not possessed by any human in the real life. However, through this lyric, the author tries to make an imaginative situation in 
which human has demons. As the data uses an illogical idea, the data above is categorized as a hyperbole.

This data has a personal feeling. The feeling refers to a negative emotion as it is associated with demons. Hence, this data is considered to have affective meaning. Furthermore, how the demons represent an anxiety and negative emotion of someone senses a connotative meaning. Therefore, this data is concluded to have affective and connotative meanings.

\section{Data 3:}

\section{[3] The scars on your heart are yours to atone (Empire Let Them Sing)}

There is an exaggeration found in the data above. The exaggerated idea is in the phrase "the scars on your heart". In this song lyric, the word 'heart' refers to a place where emotions are felt. On the other hand, a scar is defined as a mark remaining after injured tissue has been healed, as on the skin. Therefore, as a scar usually appears on our physical feature, it is an illogical thing to have a scar on an unseen part of our body, in this case is our emotion. However, through this expression, the author tries to refer that scar as a bad and hurtful feeling experienced by someone. As the data uses an exaggeration, it is considered as a hyperbole.

This data cannot be understood literally. Having a metaphorical knowledge is needed to interpret the meaning properly. This lyric means that every sin that human does is a self-responsibility, do not judge and do not try to help. Therefore, this data is considered to have connotative meaning.

\section{Data 4:}

[4] My secrets are burning a hole through my heart (Sleepwalking)

The data above contains an exaggerated expression. The exaggerated point is that a heart can have a hole by being burnt. The heart, a place where emotions are felt, is impossible to be burnt. Moreover, secrets cannot burn a thing. Therefore, secrets that burn a hole through a heart is an irrational thing. The literal meaning of this lyric line is that the author's secrets, as they are very painful, can create a hole through his heart that causes an emptiness in his heart. However, after analyzing it metaphorically, it actually means that holding many secrets make him feel hard and suffered mentally. Using an exaggerated idea, the data is categorized to be a hyperbole.

This data cannot be interpreted in a literal way. The meaning of the phrase 'a hole through my heart' needs to be analyzed metaphorically. It implies a hurtful feeling. This meaning is categorized to be a connotative 
meaning. Moreover, there is also a personal feeling that the author tries to deliver through the lyric in which he creates an emotion of sadness and painful. Hence, this data also contains affective meaning. In conclusion, this data has connotative and affective meanings.

\section{Data 5:}

\section{[5] I'm bleeding out every word you said (Go to Hell for Heaven's Sake)}

The data above states that people can bleed because of someone's word. Usually, people can bleed if there is a sharp tool cutting their skin. Although there is a quote saying that words can be sharper than a knife, the reality shows that someone cannot bleed because of words. Hence, it is illogical. However, in this lyric line, the author is known to hear some words he thinks to be very harsh and hurtful; hence, through this lyric, he tries to show his hurt feeling towards those words. As the line uses an illogical idea to portray his feeling, this data is considered as a hyperbole.

There is a connotative meaning in this data shown in 'bleeding out every word you said' that indicates a feeling of hurt. The hurt is not physical but more into mental and emotional. Since the author tries to deliver to the audience about his hurt and sadness because of the words he hears, this data is also considered to have affective meaning. In conclusion, the data contains connotative and affective meanings.

\section{Data 6:}

[6] Did you catch your own reflection in the knife my mother held? Or the hell in my father's eyes? (Can You Feel My Heart)

There is an exaggerated phrase 'the hell in my father's eyes' in the data above. A hell is believed as a place where devils live and where sinful people go after they die. It is often portrayed as a scary place where the spirits get their punishment toward the sins they did in their life. However, no one exactly knows how the hell looks like. Moreover, an object inside human's eyes that can give someone a vision of hell does not exist in the reality. Hence, it is an exaggerated thing. From this lyric, the author portrays that making sin or mistake is something bad that will make people receive a judgment by God, known as Karma, that human needs to realize. Using the concept of eye's reflection, the author tries to show his sense of awareness toward it. Due to this, the data above is considered as a hyperbole.

The data shows an expression that cannot be interpreted literally. When the lyric states 'the hell in my father's eyes', it does not mean the actual vision of hell in a father's eyes. It indicates a reflection that someone can use to realize their bad deeds. Hence, this data is categorized to have a connotative meaning. 


\section{Data 7:}

\section{[7] Will burn just like a thousand suns (The House of Wolves)}

The data above states that the number of the sun can be thousands. However, in fact, the sun is only one in the Milky Way. Exaggerating the number of suns aims at strengthening the meaning of the lyric. Through this lyric, the author shows that something done for a bad purpose will be nothing at the end of the day. Based on this analysis, the data above is considered as a hyperbole.

The data cannot be interpreted well only by looking its lexical meaning. It states 'a thousand suns' which, in fact, do not exist. Based on the analysis, the meaning of 'a thousand suns' in the lyric can indicate something that can be dissolved because it is made for a bad purpose. Therefore, the meaning of the data is considered as connotative meaning.

\section{Data 8:}

\section{[8] I'm at the edge of the world (Sleepwalking)}

The data above uses the term 'the edge of the world'. The edge of the world is defined as the point where the world begins or ends. However, until today, no one knows about where it is. Hence, it is an exaggeration. However, it is found that the 'world' in this lyric does not refer to the real world where the living creatures live, but the author's world or life. This line shows that the author is at the end of his world. It can be said that, only because of an action, the author's life might end soon. Due to this, this data is considered as a hyperbole.

The meaning of the data cannot be interpreted literally. The edge of the world is unknown. Hence, saying someone is at the edge of the world, or in this case is their life, indicates something related to someone's psychological and emotional condition. This part of lyric implies the author is in a critical situation. Therefore, the data has a connotative meaning.

\section{Data 9:} Sake)

[9] It's moments like this where silence is golden (Go to Hell for Heaven's

The data above states that 'silence is golden'. However, silence is an abstract thing which indicates a situation of no sound. It cannot be seen but heard. On the other hand, golden is the color of gold that can be seen by people's eyes. Hence, it is an illogical idea to say silence is golden. Furthermore, as golden also indicates something precious, this line of lyric can be understood as silence is precious. However, saying silence as a precious thing is sound exaggerated because the term 'precious' is usually 
referred to wealth or happy family, something that causes people happy. Based on this analysis, this data is categorized to be a hyperbole.

The data contains a clause that needs a metaphorical knowledge to interpret it. It states 'silence is golden' which, after the analysis, is understood to have a meaning of silence is precious. Hence, this data has a connotative meaning. Moreover, 'precious' is defined as something that makes someone happy. The author shows his personal feeling that he thinks silence is an enjoyable thing for him. This implies an affective meaning. In conclusion, this data is considered to have connotative and affective meanings.

\section{Data 10:} Sake)

[10] I'm burning down every bridge we made (Go to Hell for Heaven's

The data above states that 'we' which is referred to the author with someone can make a bridge which, in fact, it needs a complex process to build it. Hence, it is an exaggerated idea to say that the author can make a bridge. However, the term 'bridge' here is not the actual bridge on which people use to cross one area to another, but a social relation. Furthermore, burning down a bridge is an impossible to be done. Hence, it is an exaggerated idea as well. In this lyric line, burning down a bridge does not mean breaking down a bridge by burning it using fire. Connecting the meaning of the bridge as stated previously, this lyric part actually means the author breaks a relation he has made with someone or some people. It indicates his anger emotion. Using some exaggerated points, this data is considered as a hyperbole.

The data contains a meaning that cannot be understood literally. It states, 'burning down every bridge we made'. That line does not mean breaking an actual bridge using fire. Meanwhile, it is about stopping a social relation with someone. This indicates a connotative meaning. Moreover, the data also shows an emotion of anger. This lyric tries to make the listener feel the anger and disappointment until breaking a relationship is needed. As the lyric evokes someone's personal feeling, it is also categorized to have affective meaning. Therefore, this data has connotative and affective meanings.

\section{Data 11:} Sake)

[11] I'll watch you choke on the hearts you break (Go to Hell for Heaven's

The statement of 'the heart you break' in the data above is exaggerated. It is an impossible thing because breaking means an action of separating things into pieces and heart itself cannot be broken that way. It 
is because a heart is not a fragile thing like a ceramic plate or a glass that can be broken into pieces. In this lyric part, breaking hearts indicates to someone's hurt feeling and sadness because of hurtful action done by someone. As this data uses an exaggeration, it is categorized as a hyperbole.

The part of 'the hearts you break' in the data cannot be interpreted literally. It means hurting someone's feeling. The line of the lyric means the author will watch people hurt themselves while hurting others. This meaning is considered as connotative.

\section{Data 12:}

\section{[12] I've heard these lines a thousand times (Seen It All Before)}

There is a clear exaggeration in that lyric part shown in the data above. The use of 'a thousand' indicates an exaggeration. It is because hearing something for a thousand times is hardly possibly done by someone. The author may hear a specific utterance less than fifteen times. However, because of being tired of hearing it, he says it as a thousand times. This lyric portrays a condition of the author who has been bored of some words repeatedly said by someone for all the time. Using an exaggeration, this data is considered as a hyperbole.

The data has a phrase that cannot be interpreted literally. When the author states 'a thousand times', it does not mean that he actually hears the words that many. Stating something for a thousand times is a barely possible thing to be done by someone. Therefore, to understand the lyric, the term 'a thousand times' means too many times. Hence, this data is categorized as a connotative meaning.

\section{Data 13:} Sing)

[13] Cause Heaven's full and Hell won't have me (and the Snakes Start to

The data above talks about heaven and hell, two places that no one ever proves their existences. Mentioning that there is no space in heaven for the author is an exaggeration. Moreover, stating that someone will not be accepted in hell is also a barely possible thing. Both cannot be ensured as human does not know how the heaven and hell work. Therefore, stating such conditions is an exaggerated idea. Therefore, this data is categorized to be a hyperbole.

The meaning of each word of the lyric can be seen in the dictionary. In the part 'heaven is full', there is no hidden meaning behind it. In the part 'hell will not accept him', there is no hidden meaning behind it either. They are based on their lexical meanings. Therefore, this data has a 
conceptual or denotative meaning. However, a connotative meaning can be interpreted when the whole line is indicated as no place after life is suitable for the author. In conclusion, this lyric contains conceptual and connotative meanings.

\section{CONCLUSION}

Based on the foregoing analysis about hyperbole and the meanings found in the song lyrics of Sempiternal album by Bring Me the Horizon, there are thirteen data of hyperboles found in seven songs of the album. The figurative language of hyperbole was used by the singer to provide special effect such as to magnify and strengthen certain point within a lyric. The hyperbole also added aesthetic effect to the songs, thus the songs are unique and interesting. Regarding the meaning, there are three kinds of meaning found in this data, namely conceptual, connotative, and affective. The dominant meanings found are connotative and affective due to the words used in the lyrics cannot be interpreted lexically and have hidden meanings and the lyrics are closely related with the personal experience of the singer. The meanings found in the song is more about disbelief in religion and depression. This study can be used as a reference for future research about similar topic of hyperbole or other figurative languages. Through this research, society can understand the songs of Bring Me the Horizon in Sempiternal album.

\section{REFERENCE}

Ardiansyah, Nur Muhammad and Mandarani, Vidya. (2018). An Analysis of Figurative Language Elements upon an American Short Story Entitled "The Monkey's Paw". Journal of English Educators Society, $3(1), 13-22$.

Genius. 2018. Accessed on January 16, 2021, from https://genius.com/albums/Bring-me-the-horizon/Sempiternal

Harfiza. (1997). Semantics: Words without Meaning is Meaningless. UKM.

Hook, J.N. (1989) The Quite Virtue Speaks: An Intervation To Promote Humility. Journal of psychology and theology 71 (1)

Hornby, A.S. Oxford Advanced Learner's Dictionary of Current Language, Oxford: Oxford University Press, 1995.

Huang, Ying. (2020). Hyperboles in Advertising: A Serial Mediation of Incongruity and Humour. International Journal of Advertising, 39(5), 719-737.

Hurford, James R. and Heasley, Brendan. 1983. Semantics: A Coursebook. Cambridge University Press. 
Knickerbocker, K. L. (1963). Interpreting Literature Revised. New York: Holt, Rinehart \& Winston

Leech, Geoffrey. (1974). Semantics. Auckland: Penguin Books.

Leech, Geoffrey. (1981). Semantics: Second Edition. Harmondsworth: Penguin

Lyons, J. (1995). Language and Linguistics. Cambridge: Cambridge University Press.

McCarthy, Michael and Carter, Ronald. (2004). There's Million of Them": Hyperbola in Everyday Conversation. Journal of Pragmatics, 36(2), 149-184.

Setiawati, Wilya and Maryani. (2018). An Analysis of Figurative Language in Taylor Swift's Song Lyrics. Professional Journal of English Education, 1(3), 261-268.

Wibisono, Radna Tulus and Widodo, Pratomo. (2019). An Analysis of Figurative Language in Online Short Story Posted on the Jakarta Post. Prasasti: Journal of Linguistics, 4(2), 156-165. 